\title{
Profile
}

\section{Health Action International: networking for rational drug use}

\author{
Catherine Hodgkin \\ Coordinator HAI-Europe
}

\section{How did HAI start?}

"May 27 to 291981 were memorable days for me. Those three days in May made me, a medical professional, aware of the enormous potential the non-medical NGOs had in helping policy makers and governments rationalise the global pharmaceutical supply system." (Dr K. Balasubramaniam, then employed by UNCTAD, now one of HAI's three international coordinators)

In 198150 people from health, development, and consumer organisations met in Geneva. They were brought together by a shared concern about the way in which pharmaceuticals were being misused and about unsatisfactory standards of industry promotion and marketing. At this meeting they established Health Action International. At the time it was described as an "international antibody" to the worst effects of international pharmaceutical marketing but in the ten years of its existence it has become much more than that and has grown to be a powerful advocate of consumer interests on a broad range of issues relating to drugs and health.

Since the 1960s there had been important developments in perceptions of how drugs could best contribute to health. The thalidomide disaster was just one of several events which underlined the need to regulate what drugs are marketed and how they are used. The WHO had produced a list of around 200 essential drugs which met common health needs - a valuable tool for countries struggling with the bewildering array of drugs on the market. In spite of this progress the reality in developing countries was not changing significantly. Most people could not afford medicines and if they did have access to them the chances were high that they would be sold a drug which was ineffective, expensive or dangerous.

Many organisations and individuals were working for a more rational use of drugs but they were often isolated and hampered by lack of information and resources, they had no means of making their voice heard at an international level and no means of learning from each other. HAI was established to provide a voice and a forum for these groups and to act as an additional force in a field where discussions had traditionally been dominated by government and industry. 


\section{How does it work?}

The HAI Network is built around the simple idea that if many organisations and individuals pool their expertise, skills, resources and experiences and cooperate to achieve a common goal, they become a powerful force even if their financial resources are small and their organisational structure limited. Cooperation between groups in industrialised and developing countries is important, particularly when it comes to influencing policy at international level or monitoring the standards set by multinational companies.

The HAI Network today is made up of around 150 consumer, health and development groups working in 60 countries. The groups are varied - ranging from powerful NGOs to small groups of isolated health workers or concerned individuals.

There are three coordinating centres; in Asia, Latin America and Europe. The coordinating centres maintain close contact with each other and with HAI participants in six continents. The coordinating centres are there to serve the needs of the groups, to respond to developments at national or regional level and to coordinate international advocacy and campaigning. Participants meet at regional or international meetings to discuss common concerns and develop joint strategies. HAI groups are autonomous and self-reliant and drugs are often only one component of their work.

The Network Newsletter-HAI News is published 6 times a year. In addition there are regional and national Newsletters. In Europe information is increasingly available on-line.

\section{What does the Network do?}

HAI works through research, action campaigns, training and advocacy to promote a more rational use of drugs. HAI publications are used by health workers, government regulatory agencies and consumers around the world. Research carried out by HAI groups contributes to better education about drugs and campaigns initiated by HAI have led to the withdrawal of various dangerous or obsolete drugs. The range of activities is wide and groups vary in their areas of work and expertise. A few examples serve to give an idea of this diversity.

The HAI Problem Drug Pack was first published in 1986. The pack, which examines categories of known "problem drugs" such as appetite stimulants and antidiarrhoeals, has been translated into six languages, reprinted many times and used all over the world both as a campaigning tool and to train health workers.

HAI participants served on WHO Expert Committees which drew up "Guidelines for the Development of National Drug Policies" and "Ethical Criteria for the Promotion of Medicinal Drugs" and they also participate in other WHO consultations.

In Bolivia the local HAI group is involved in education work in schools. They distribute comic strips warning against the use of inappropriate antidiarrhoeals and organise follow-up 
discussions teaching children about oral rehydration therapy and the benefits of breast feeding.

In Asia several countries cooperated in a children's medicines project. Prescriptions were monitored and pharmacists observed to obtain an accurate picture of what drugs were prescribed for common childhood ailments. The researchers gained a much clearer understanding of the causes and scale of irrational drug use and were able to use the results to develop appropriate educational strategies.

In Europe HAI groups work together to encourage the EC to adopt regulations restricting the export of products not licensed in Europe. They also organise working groups to monitor the development of new EC legislation.

In Germany a street theatre group toured the country performing short sketches to illustrate problems associated with the irrational use of drugs.

In Geneva HAI advocates meet regularly with delegates attending the World Health Assembly and argue for strong leadership from the WHO on drug issues.

HAI, together with others, has been campaigning internationally to end the inappropriate use of antidiarrhoeals. Several of the most widely misused antidiarrhoeals have been withdrawn from the market.

\section{What has been achieved?}

There is still much work to be done by HAI and others working in this field. The WHO estimated in 1988 that between a quarter and a half of the world's population still has no access to basic essential drugs. Debt and the economic problems facing many developing countries mean that health care services are under increasing pressure. In spite of guidance given by the WHO, few countries have acted effectively to control drug promotion and in most developing countries drug regulatory control is rudimentary. Re-educating prescribers and consumers to prescribe and use drugs more rationally is a slow and gradual process.

However, HAI can claim to have made a real impact since its foundation ten years ago, especially in promoting a process of reform and change within some companies and in the field of policy advocacy. The essential drugs concept has gained wide acceptance, steps have been taken to encourage the distribution of independent information on drugs, some of the worst drugs have been withdrawn. Perhaps most importantly there is a wide acceptance of the fact that consumer advocates have a place in drug policy discussions and that what is at issue is not the safety of drugs but the safety of people using them. Involving consumers in policy decisions, providing appropriate consumer information on drugs and educating people in the principles of rational drug use, these are all essential steps in maximising safety and reducing risk in medicine.

Additional information is available on request from:

HAI-Europe

Jacob van Lennepkade $334 \mathrm{~T}$

1053 NJ Amsterdam Tel. $31(0) 206833684$

The Netherlands $\quad$ Fax $31(0) 206855002$ 